\title{
Age-related Resistance of Diverse Cucurbit Fruit to Infection by Phytophthora capsici
}

\author{
Kaori Ando, Sue Hammar, and Rebecca Grumet ${ }^{\mathbf{1}}$ \\ Department of Horticulture and Graduate Program in Plant Breeding and Genetics, Michigan State \\ University, East Lansing, MI 48824
}

\begin{abstract}
AdDitional INDEX words. disease, developmentally-acquired resistance, Cucurbitaceae, mature-plant resistance
Abstract. Phytophthora capsici causes severe losses in vegetable production, including many cucurbit crops. Our previous work showed that cucumber (Cucumis sativus) fruit are most susceptible to $P$. capsici when they are very young and rapidly elongating, but develop resistance as they approach full length at 10 to 12 days postpollination (DPP). In this study, fruit from seven additional cucurbit crops representing four species, melon (Cucumis melo), butternut squash (Cucurbita moschata), watermelon (Citrullus lanatus), and zucchini, yellow summer squash, acorn squash, and pumpkin (Cucurbita pepo), were tested for the effect of fruit development on susceptibility to $P$. capsici. Field-grown fruit of the different crops varied in overall susceptibility. Zucchini and yellow summer squash were the most susceptible, with the majority of fruit exhibiting water-soaking symptoms within 24 hours postinoculation. Fruit from all of the crops exhibited size-related decrease in susceptibility, but to varying degrees. Cucumber had the most pronounced effect. In infested fields, cucumber fruit were found to be most frequently infected at the blossom end. Comparison of the peduncle and blossom end showed a difference in susceptibility along the length of the fruit for cucumber, butternut squash, and zucchini. Greenhouse-grown, hand-pollinated pumpkin, acorn squash, and butternut squash showed an age-related decrease in susceptibility similar to field-grown fruit. For all of these fruit, a pronounced reduction in susceptibility accompanied the transition from the waxy green to green stage at $\approx 3$ to 8 DPP.
\end{abstract}

In recent years, Phytophthora capsici has become an increasingly severe disease of a wide range of vegetable crops, including cucurbit crops, where it can cause devastating yield losses (Babadoost, 2004; Hausbeck and Lamour, 2004). In some cases, losses of up to $100 \%$ have been reported and growers have had to abandon production fields (Babadoost, 2004). P. capsici is a soil-borne oomycete pathogen that can cause diseases in many plant organs and at various growth stages of the host (e.g., damping-off on processing pumpkin and fruit rot on cucumber). It is favored by wet and warm environments and can spread with water such as rain splash or irrigation. The symptoms observed during the disease progression of $P$. capsici-infected fruit are a depressed fruit surface with a water-soaked appearance followed by white cottony mycelium covering the affected region.

Control of the disease by chemical and cultural practices remains a challenge. Resistance to the common fungicide, mefenoxam, has emerged (Lamour and Hausbeck, 2000). Rotation to a nonhost crop is of limited value because oospores of $P$. capcisi can survive in the soil for a long period of time, up to 10 years (Hausbeck and Lamour, 2004). Wider plant spacing, cover crops, trellises, or variant architectural phenotypes may help to control the disease by facilitating better fungicide

Received for publication 23 Jan. 2009. Accepted for publication 12 Mar. 2009. The work was in part supported by MSU-GREEEN, The Pickle Seed Research Fund, USDA-CSREES Award No. 2006-34572-16902, and Michigan Agricultural Experiment Station Hatch Project 01966 (Phytophthora Research, MI).

We thank Dr. Bernard Zandstra and Seminis Vegetable Seed Inc. for providing seeds, Drs. Mary Hausbeck and Amanda Gevens for providing the Phytophthora capsici isolate, and Drs. Jianjun Hao and Mathieu Ngouajio for helpful reviews of the manuscript. In addition, we thank Bill Chase, Gary Mitchell, Matt Duncan, and the field crew of the Hausbeck laboratory for their help in the field. ${ }^{1}$ Corresponding author. E-mail: grumet@msu.edu. coverage, modifying the microclimate, or reducing contact with the inoculum-containing soil, thereby facilitating disease avoidance (Ando and Grumet, 2006; Ngouajio et al., 2006; Ristaino et al., 1997; Wang and Ngouajio, 2008). However, these methods can be difficult to implement in a commercial setting. The most desirable solution would be to find resistant cultivars, but this has met with mixed success. Efforts are underway to identify sources of resistance in Cucurbita pepo (Padley et al., 2008) and to introgress resistance from the wild Cucurbita species, C. lundelliana, into C. mocshata (Padley et al., 2009). To our knowledge, there have not been studies to identify sources of resistance to $P$. capsici in watermelon or melon. Screening of a diverse collection of cucumber germplasm accessions for fruit resistance to $P$. capsici has not identified any resistant genotypes to date (Gevens et al., 2006).

In the course of screening for resistance in cucumber, we observed an effect of fruit age on susceptibility (Gevens et al., 2006). Testing of hand-pollinated fruit of known ages showed that most fruit younger than $10 \mathrm{~d}$ postpollination (DPP) exhibited sporulating lesions at $4 \mathrm{~d}$ postinoculation (DPI), whereas fruit older than 14 DPP generally remained symptomfree. Fruit of intermediate ages (10-12 DPP) often exhibited water-soaked regions without sporulation. Interestingly, the transition from susceptible to resistant appeared to coincide with the end of the period of rapid fruit elongation, suggesting that physiological changes associated with fruit growth and development might explain changing susceptibility among cucumber fruit of different ages. The effect of fruit age was observed for several different cucumber cultivars and accessions. In addition, field-grown cucumbers, harvested to test a range of fruit sizes, exhibited the same trend as observed with greenhouse-grown fruit. These results indicated that there are changes in the degree of susceptibility among fruit of different ages in greenhouse and field conditions, and that the age-related 
decrease in susceptibility is not genotype specific. Age-related resistance, also known as adult plant resistance, or developmentally related resistance, in which a maturing plant or plant organ (e.g., leaf or fruit) becomes less susceptible to pathogens, has been observed in many plant-pathogen systems, including diseases caused by fungi, oomycetes, bacteria, and viruses (Develey-Riviere and Galiana, 2007; Panter and Jones, 2002; Whallen, 2005). Age-related resistance can have implications for appropriate disease control strategies and timing for fungicide application to target susceptible stages of fruit development for protection.

In this study, we tested whether the age-related resistance to $P$. capsici also occurs in fruit of other cucurbit crops. Detached fruit spanning a range of ages from eight crops including cucumber, melon, watermelon, butternut squash, and four C. pepo crops, zucchini, yellow summer squash, acorn squash, and pumpkin, were tested for response to inoculation with P. capsici.

\section{Materials and Methods}

Cucurbit Fruit ANd inoculation. Cucumber 'Vlaspik' (Seminis Vegetable Seed, Oxnard, CA), muskmelon 'Odyssey' (Rispens Seeds, Beecher, IL), butternut squash 'Waltham' (Seedway, Hall, NY), watermelon 'Crimson Sweet' (Seedway), zucchini 'Black Beauty' (Seedway), yellow summer squash 'Horn of Plenty' (Seedway), acorn squash 'Royal Acorn' (Seeds of Change, Santa Fe, NM), and pumpkin 'Baby Pam' (Seedway) were grown in a field with no history of $P$. capsici infestation at the Michigan State University (MSU) Horticulture Teaching and Research Center, East Lansing, MI, during Summer 2006. Seeds were planted into Marlette fine loam soil in 15-m rows, with $3.3 \mathrm{~m}$ between rows, and $50 \mathrm{~cm}$ spacing within rows, except cucumber, which was planted at $4 \mathrm{~cm}$ spacing within rows. Local standard commercial production guidelines were followed for insect and weed control (Bird et al., 2005). Plastic mulch was used to suppress weeds. Irrigation was provided by rain or trickle irrigation to provide $25 \mathrm{~mm}$ per week.

Fruit were harvested on at least two dates during the period of July to September for each crop to provide a total of 45 to 93 fruit per crop, representing a range of stages of development as assessed by fruit size and appearance. Harvested fruit were washed with distilled water, air-dried, and measured for length and width. The fruit were then inoculated with 6-mm-diameter plugs of 7- to 11-d-old mycelium culture of P. capsici, isolate OP97 (Gevens et al., 2006). Mycelial agar plugs were placed $\approx 2 \mathrm{~cm}$ from the peduncle and blossom end of each fruit and covered with an inverted lidless $1.5-\mathrm{mL}$ microcentrifuge tube held in place with petroleum jelly different at $P \leq 0.05$ (LSD). as per Gevens et al. (2006). Inoculated fruit were incubated at room temperature in sealed aluminum trays with moist paper. Each fruit was monitored daily for 10 DPI and scored for stage of disease progression $(1=$ no symptoms, $2=$ water soaked, $3=$ sporulation).

Greenhouse studies were also performed for acorn squash 'Autumn Delight' (Siegers Seeds, Holland, MI), butternut squash 'Waltham', and pumpkin 'Baby Pam' in the MSU Research Greenhouse (East Lansing, MI) during Spring and Summer 2008. Seeds were sown into 38-L plastic pots filled with BACCTO (Michigan Peat, Houston, TX) media and fertilized with $300 \mathrm{mg} \cdot \mathrm{L}^{-1}$ nitrogen from $20 \mathrm{~N}-8.8 \mathrm{P}-16.6 \mathrm{~K}$ water-soluble fertilizer (Peters Professional ${ }^{\circledR}$ 20-20-20 General Purpose; Scotts, Marysville, $\mathrm{OH}$ ) once per week. Temperature was kept between 21 and $25^{\circ} \mathrm{C}$; supplemental lights were used to provide an 18-h light period. Pest control was performed according to the standard management practices in the greenhouse. Fruit were hand-pollinated daily over a $45-\mathrm{d}$ period to provide a set of fruit of known ages that could be harvested and tested simultaneously. The experiments were repeated at least twice for each crop with 16 plants per crop per experiment to provide a total of 67 to 79 fruit per crop. Harvested fruit were measured for length and width, examined for color and external surface properties, and then processed for inoculation and scored for symptoms as described above. Data were analyzed by ANOVA using SAS (version 9.1; SAS Institute, Cary, NC) with mixed procedures. When appropriate, LSD was used for multiple comparisons. Regression analysis was performed using SigmaPlot 8.02 (SPSS, Chicago). Blossom/peduncleend comparisons of the same fruit were performed by using chi-square contingency analysis on two trials of the same subject according to Steel and Torrey (1960).
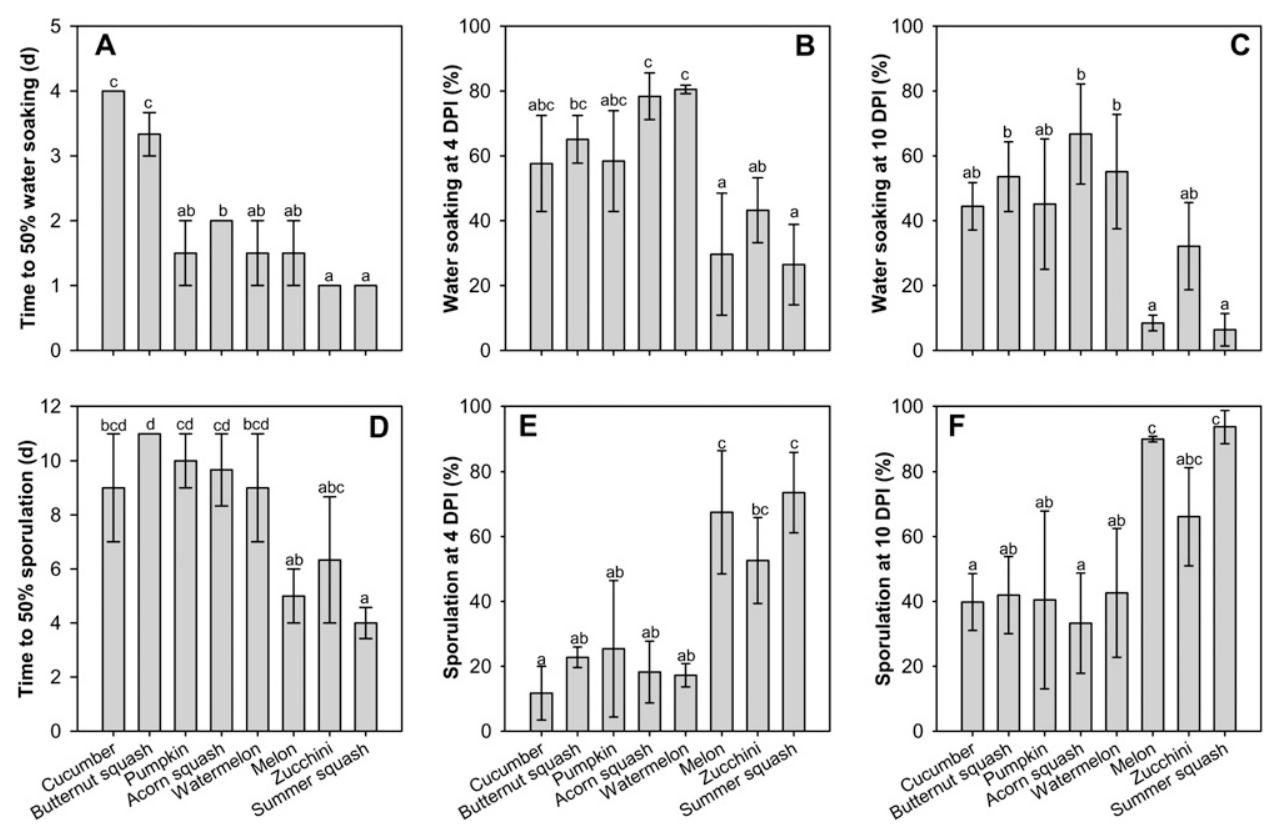

Fig. 1. Response of different cucurbit fruit to inoculation with Phytophthora capsici. (A and D) Days after inoculation for $50 \%$ of the fruit to exhibit water-soaked (A) or sporulating lesions (D). (B and C) Percentage of fruit showing water-soaking symptoms at $4 \mathrm{~d}(\mathbf{B})$ and $10 \mathrm{~d}(\mathbf{D})$ postinoculation (DPI). (E and F) Percentage of fruit showing sporulation at 4 DPI $(\mathbf{E})$ and 10 DPI $(\mathbf{F})$. Each value is the mean of fruit from two or three replicate harvest dates (where error bars are absent, the days to symptom development on $50 \%$ of the fruit was the same for each replicate date). Each bar is the mean \pm SE of 45 to 93 fruit. Bars with the same letter are not significantly 


\section{Results}

Susceptibility of CUCURbit Fruit to $\boldsymbol{P}$. CAPSICI. An effective and highly reproducible methodology to directly evaluate fruit response to inoculation with $P$. capsici was developed by Gevens et al. (2006). Use of the detached fruit assay provides a consistently high level of inoculum, optimal infection conditions to prevent possible escape from infection (i.e., possible misinterpretation as resistance), and controlled time of inoculation of fruit of known size or age. Infected fruit show a disease progression of water-soaking symptoms followed by sporulating lesions. The frequency with which infection occurred, or if it occurred, progressed beyond the water-soaking stage to sporulation, which is necessary for further spread of infection, varied depending on fruit type and age. Fruit of different cucurbit crops exhibited variability for overall susceptibility (Fig. 1). When fruit of all sizes were grouped together, summer squash, zucchini, and melon were the most susceptible, with the greatest percentage producing sporulating lesions at 4 and 10 DPI and the shortest time to 50\% sporulating fruit (Fig. 1, D-F). Summer squash and zucchini were also notable for rapid development of water-soaking symptoms; more that $50 \%$ of the tested fruit exhibited water soaking by 1 DPI (Fig. 1A). On summer squash, water soaking symptoms occurred on $85 \%$ of the tested fruit by 1 DPI. Watermelon, acorn squash, pumpkin, butternut squash, and cucumber were less susceptible with rare sporulation of $P$. capsici at 4 DPI (Fig. 1E). These fruit were more likely to develop water-soaking symptoms that did not progress to sporulation, even at 10 DPI (Fig. 1, B, C, and $F$ ).

EFFEct of FRUIT SIZE AND AGE. For almost all of the crops tested, susceptibility decreased with increasing fruit size, but to varying degrees (Fig. 2; $P<0.01$ for all crops except melon and watermelon). Cucumber showed the most dramatic effect, with near complete resistance as the fruit developed. Butternut squash, pumpkin, and acorn squash also exhibited reduced susceptibility with increasing size, but not as completely as with cucumber (i.e., fewer had no symptoms). Watermelon, melon, zucchini, and summer squash remained more susceptible. There was a modest decline for zucchini and summer squash with increasing size, but the majority of large fruit still exhibited water soaking (disease rating $>2$; Fig. 2, E-H).

To more carefully examine the effect of fruit development on disease susceptibility, greenhouse-grown, hand-pollinated butternut squash, pumpkin, and acorn squash fruit of known ages were tested for response to $P$. capsici inoculation. All three crops also showed strong age- and size-related decreases in susceptibility to $P$. capsici (Fig. 3), similar to what we had observed previously in the greenhouse for cucumber (Gevens et al., 2006) and with field fruit from this study. The majority of instances of $P$. capsici sporulation occurred on fruit in the first few DPP, 0 to 3 DPP for acorn squash, 0 to 5 DPP for butternut squash, and 0 to 8 DPP for pumpkin. Older fruit exhibited water
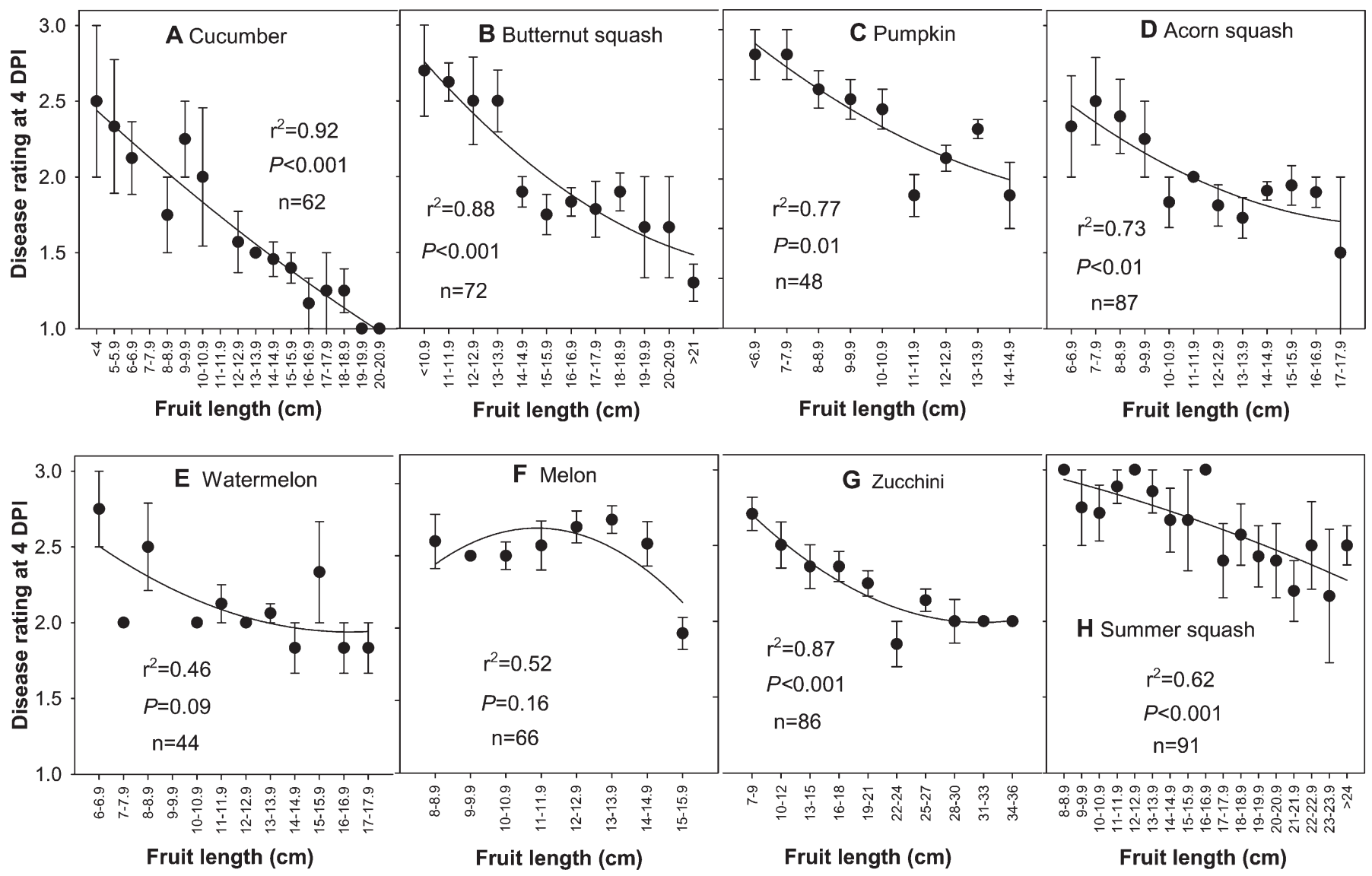

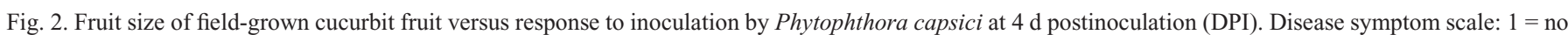
symptoms, $2=$ water soaking, $3=$ sporulation. Each point is the mean $\pm \mathrm{sE}$ of 2 to 8 fruit in a given size class. Regression lines, $\mathrm{r}^{2}$, and $P$ values, and total number of fruit tested (n) are indicated in each panel. 

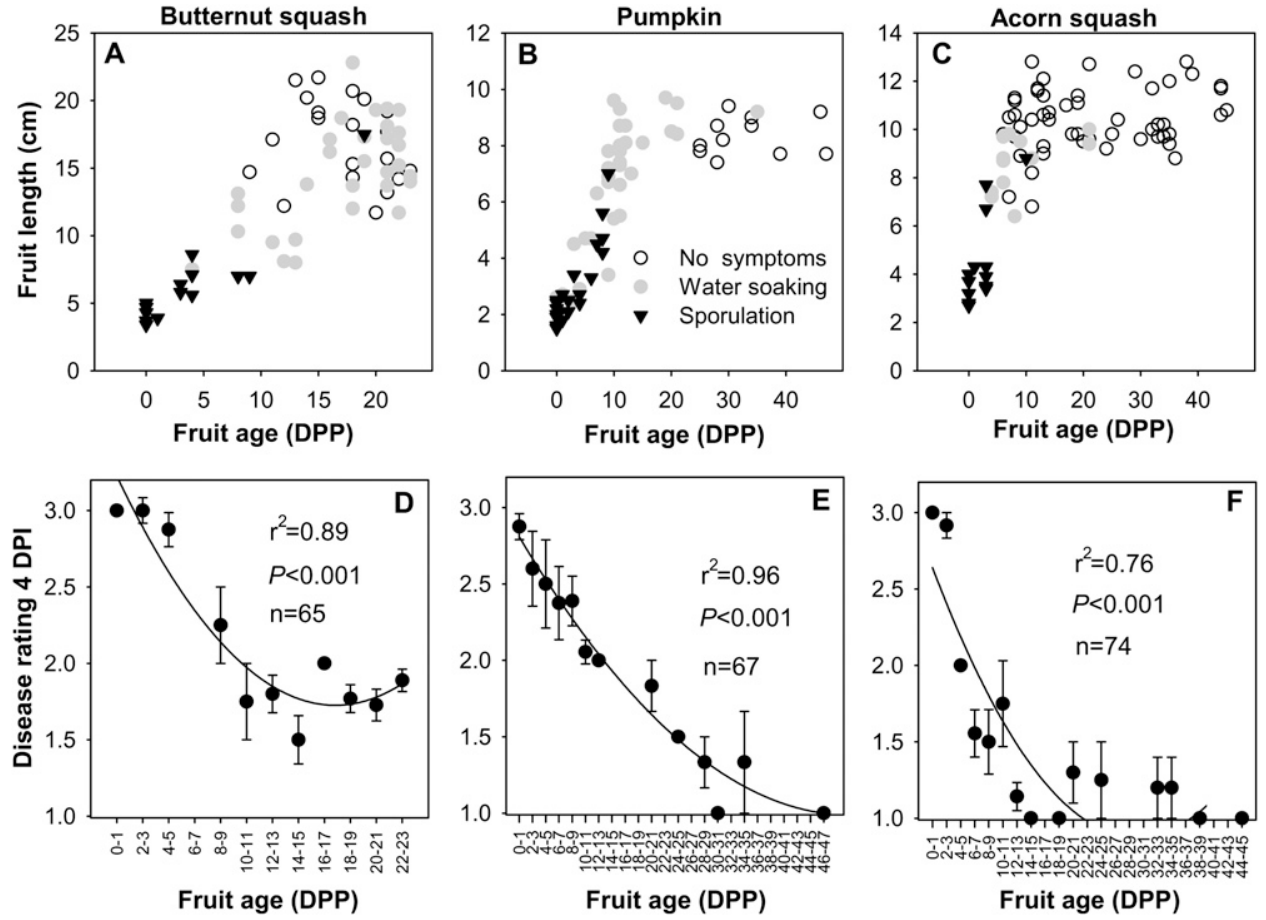

Fig. 3. Relationship between fruit age and size and response to inoculation by Phytophthora capsici at $4 \mathrm{~d}$ postinoculation (DPI) for greenhouse-grown fruit. (A-C) Response of butternut squash (A), pumpkin (B), and acorn squash (C) fruit to $P$. capsici inoculation with respect to fruit age and length. (D-F) Mean disease rating $( \pm \mathrm{SE})$ of butternut squash $(\mathbf{D})$, pumpkin $(\mathbf{E})$, and acorn squash $(\mathbf{F})$ fruit in relation to fruit age. Each data point is the mean of 2 to 16 fruit. Disease rating scale: $1=$ no symptom, $2=$ water soaking, $3=$ sporulation. Regression lines, $\mathrm{r}^{2}$, and $P$ values, and total number of fruit tested (n) are indicated in each panel.

soaking without sporulation, or did not show any symptoms of infection.

The decrease in susceptibility corresponded with visible changes in exocarp properties associated with fruit development (Table 1). Very young fruit of all crops were green and very waxy, and virtually all fruit at this stage produced sporulating lesions. After a few days (3-4 d for acorn squash and butternut squash, $10 \mathrm{~d}$ for pumpkin), they lost wax but remained green. Susceptibility decreased between waxy green and green fruit stages for all three crops where fruit developed water-soaked lesions that did not go on to sporulate.
Each crop subsequently underwent color change/development according to their maturity type. Size did not increase significantly once color change began (Table 1). Butternut squash had little decline after the green nonwaxy stage; the majority of fruit still exhibited water-soaking symptoms. For pumpkin, there was no significant difference in susceptibility between green and green/ orange stage; however, there was further significant decrease upon turning orange (water soaking decreased to $42 \%$ ). Acorn squash showed a further decrease in susceptibility when turning from green to black as evidenced by a decrease in the percentage of fruit exhibiting water soaking (from $57 \%$ to $8 \%$ ).

EFFECT OF FRUIT POSITION. Examination of $P$. capsici-infected cucumber fruit in the field led to the observation that field-grown cucumbers are typically covered with mycelium on the blossom end of the fruit rather than the peduncle end (Fig. 4). We speculated that this observation may be due to the tendency of the blossom end to come into contact with the inoculumcontaining soil sooner than the peduncle end, since our previous study (Ando and Grumet, 2006) indicated that removal of fruit from the ground can minimize disease incidence. Alternatively, there may be a difference in susceptibility within the fruit, such that the blossom end is more susceptible than the peduncle end.

To test whether there was a difference in susceptibility between the peduncle and blossom ends of the fruit, all fruit tested were inoculated on both ends (Fig. 4). Comparison of peduncle and blossom end susceptibility of the field-grown cucurbit fruit showed differences in susceptibility for cucumber, butternut squash, watermelon, zucchini, and

Table 1. Age, size, and response to inoculation by Phytophthora capsici of greenhouse-grown cucurbit fruit at various stages of development as determined by visual properties.

\begin{tabular}{|c|c|c|c|c|c|c|}
\hline \multirow[b]{2}{*}{ Butternut squash } & $\begin{array}{c}\text { Exocarp } \\
\text { color }\end{array}$ & \multicolumn{2}{|c|}{$\begin{array}{c}\text { Fruit age } \\
{[\text { mean } \pm \text { SE (DPP) }]^{\mathrm{z}}} \\
{[\text { range }(\mathrm{DPP})]}\end{array}$} & \multirow{2}{*}{$\begin{array}{c}\begin{array}{c}\text { Fruit length } \\
{[\text { mean } \pm \mathrm{sE}(\mathrm{cm})]}\end{array} \\
5.4 \pm 0.4 \mathrm{a}^{\mathrm{y}}\end{array}$} & \multirow{2}{*}{$\begin{array}{c}\begin{array}{c}\text { Fruit with } \\
\text { sporulation at } 4 \mathrm{DPI}^{\mathrm{z}} \\
{[\text { mean } \pm \mathrm{SE}(\%)]}\end{array} \\
100 \pm 0 \mathrm{a}\end{array}$} & \multirow{2}{*}{$\begin{array}{c}\begin{array}{c}\text { Fruit with water } \\
\text { soaking at } 4 \mathrm{DPI} \\
{[\text { mean } \pm \mathrm{SE}(\%)]}\end{array} \\
0.0 \pm 0.0 \mathrm{a}\end{array}$} \\
\hline & Waxy green & $1.8 \pm 0.5$ & $0-4$ & & & \\
\hline & Green/tan & $18.4 \pm 0.6$ & $12-22$ & $16.3 \pm 0.6 \mathrm{c}$ & $1.9 \pm 1.9 \mathrm{~b}$ & $93.9 \pm 3.8 b$ \\
\hline & Tan & $20.9 \pm 0.6$ & $18-23$ & $17.2 \pm 1.1 \mathrm{c}$ & $0.0 \pm 0.0 \mathrm{~b}$ & $100 \pm 0.0 \mathrm{~b}$ \\
\hline \multirow[t]{2}{*}{ Pumpkin } & Waxy green & $2.2 \pm 0.6$ & $0-10$ & $2.8 \pm 0.2 \mathrm{a}$ & $87.5 \pm 12.5 \mathrm{a}$ & $12.5 \pm 12.5 \mathrm{a}$ \\
\hline & Orange & $34.2 \pm 1.9$ & $25-47$ & $8.6 \pm 0.2 \mathrm{c}$ & $0.0 \pm 0.0 \mathrm{~b}$ & $41.7 \pm 8.3 \mathrm{a}$ \\
\hline \multirow[t]{3}{*}{ Acorn squash } & Waxy green & $1.5 \pm 0.8$ & $0-3$ & $4.1 \pm 0.7 \mathrm{a}$ & $100 \pm 0.0 \mathrm{a}$ & $0.0 \pm 0.0 \mathrm{a}$ \\
\hline & Green & $11.6 \pm 1.0$ & $4-29$ & $9.6 \pm 0.3 b$ & $3.3 \pm 1.7 \mathrm{~b}$ & $56.8 \pm 8.4 b$ \\
\hline & Black & $27.3 \pm 2.1$ & $7-44$ & $10.4 \pm 0.2 \mathrm{c}$ & $2.6 \pm 1.3 \mathrm{~b}$ & $7.9 \pm 3.9 \mathrm{a}$ \\
\hline
\end{tabular}

${ }^{\mathrm{z}} \mathrm{DPP}=$ days postpollination, DPI $=$ days postinoculation.

${ }^{\mathrm{y}}$ Means in the same column followed by the same letter are not significantly different at $P \leq 0.05$ via LSD. 


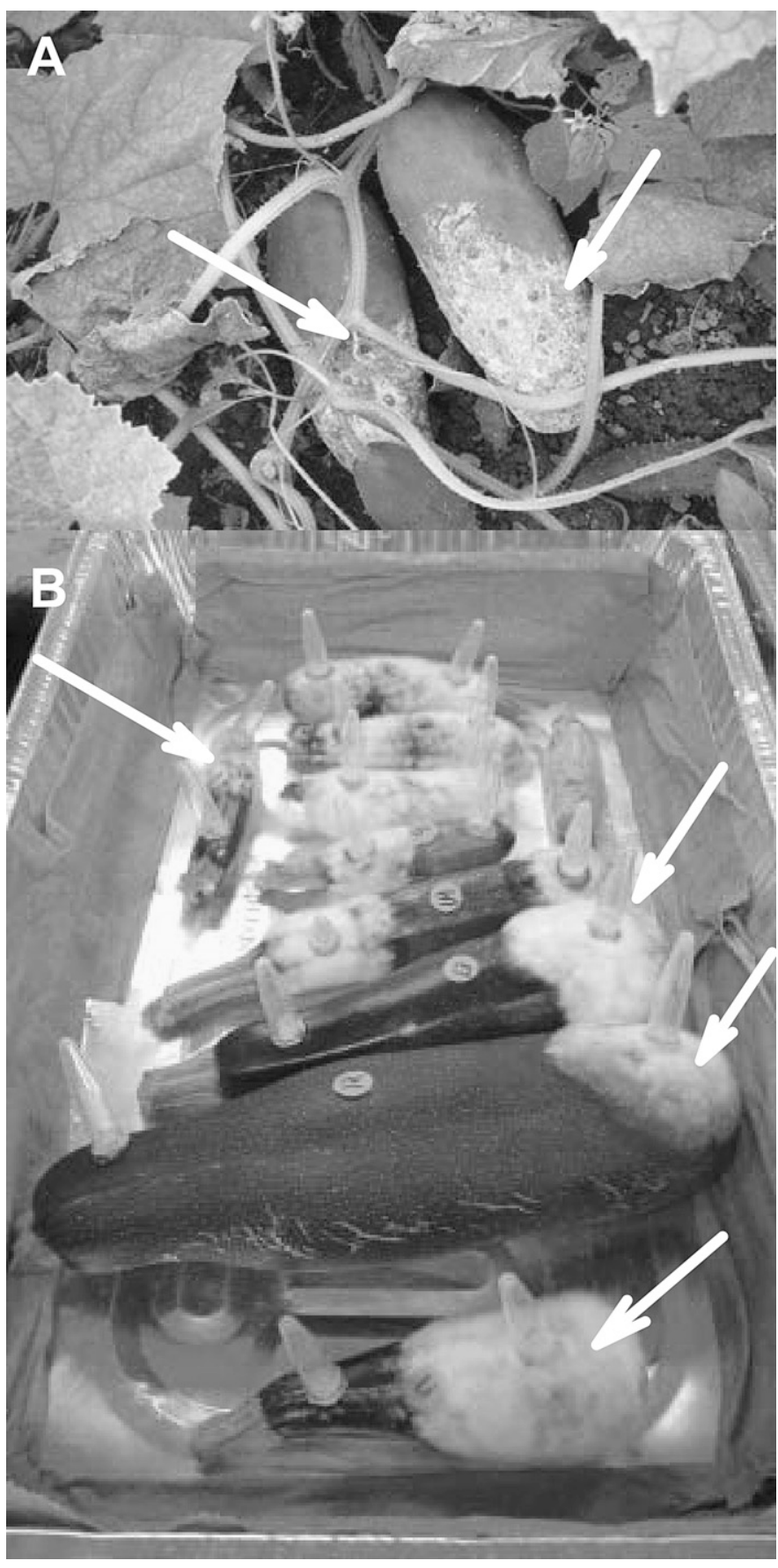

Fig. 4. (A) Symptoms of Phytophthora capsici on cucumber in the field Infection and sporulation typically occurred at the blossom end of the fruit (B) Blossom- and peduncle-end inoculation of zucchini fruit in the laboratory. Infection and sporulation occurred more frequently on the blossom than peduncle end. Arrows indicate sporulation on blossom end.

summer squash with the greatest difference for cucumber, butternut squash, and zucchini (Table 2). Significant differences between peduncle and blossom ends were also seen for greenhouse-grown butternut and acorn squashes.

\section{Discussion}

Cucurbit fruit exhibited variability for overall susceptibility to $P$. capsici as evidenced by the number of fruit infected, time to sporulation, and extent of infection (water soaking vs. sporulation). Summer squash, zucchini, and melon were the most susceptible, whereas watermelon, acorn squash, pumpkin, butternut squash, and cucumber were less susceptible. When comparing crops, susceptibility did not correlate with taxonomic classification. Of the four C. pepo crops, summer squash and zucchini were highly susceptible, whereas acorn squash and pumpkin were less susceptible. Also, thickness of rind did not correlate with the susceptibility, as muskmelon was one of the most susceptible, and cucumber one of the least.

We have previously observed that cucumber fruit grown in the greenhouse and field become less susceptible as they develop; very young cucumber fruit up to 10 to 12 DPP are the most highly susceptible (Gevens et al., 2006). Resistance in cucumber occurs after the optimal harvest age of 8 to 12 DPP. Field- and greenhouse-grown cucurbit fruit tested in this study also showed a general tendency of decreasing susceptibility with fruit development, but to varying degrees. Acorn squash, butternut squash, and pumpkin exhibited reduced susceptibility with increasing size, but not as complete as with cucumber. Despite the variations in fruit types and sizes, the transition to reduced susceptibility appeared to correlate with the end of the rapid fruit elongation, as had been observed for cucumber fruit (Gevens et al., 2006). Similar to the differences in overall susceptibility, zucchini and summer squash remained highly susceptible even as they increased in size. The majority of the watermelon and melon fruit also developed water-soaking or sporulation symptoms regardless of size.

Age-related resistance (ARR) is becoming increasingly recognized as an important component of plant defense against infection (Develey-Rivière and Galiana, 2007; Panter and Jones, 2002; Whallen, 2005). This phenomenon, which results in increased resistance as young tissues develop, is distinct from the increase in susceptibility that occurs in old, mature organs as the result of the ripening and senescence. The mechanisms of ARR are largely unknown. There is evidence that salicylic acid is important to ARR in Arabidopsis thaliana response to Pseudomonas syringae (Kus et al., 2002) and Hyaloperonospora parasitica (McDowell et al., 2005). ARR in rice (Oryza sativa) to Xanthomonas spp. (Century et al., 1999; Koch and Mew, 1991; Mazzola et al., 1994) may be related to developmentally regulated $R$ gene-mediated resistance, which is controlled post-transcriptionally or by other mechanisms. Developmentally regulated expression of single-gene-mediated resistance also has been observed for potyviruses infection of cucumber seedlings (Ullah and Grumet, 2002; Wai and Grumet, 1995). Pepper (Capsicum annum) plants also showed ARR to infection by $P$. capsici (Kim et al., 1989). The reduced susceptibility was suggested to be related to physiological changes in root and stem tissues. Similar to the response of cucumber fruit to $P$. capsisi, developing grape berries (Vitis vinifera) also showed decreased susceptibility to infection by Unicinula necator, causal agent of powdery mildew, and to Plasmopara viticola, causal agent of downy mildew (Ficke et al., 2002; Gadoury et al., 2003; Kennelly et al., 2005). Berries are highly susceptible for the first several weeks after anthesis. Developmental changes in berries, such as soluble solids content or morphological change of stomata to lenticels, were thought to be related to susceptibility changes; however, the mechanism has not been determined. In this study, acorn squash, butternut squash, and pumpkin showed changes in exocarp features that corresponded with reduced susceptibility. 
Table 2. Symptom development on peduncle and blossom ends of cucurbit crops in response to infection by Phytophthora capsici at 4 d postinoculation (DPI).

\begin{tabular}{|c|c|c|c|c|c|c|c|c|c|c|}
\hline \multirow[b]{3}{*}{ Species } & \multirow[b]{3}{*}{ Crop } & \multirow[b]{3}{*}{ Cultivar } & \multicolumn{8}{|c|}{ Symptom comparison peduncle (p) vs. blossom (b) end at 4 DPI $^{z}$} \\
\hline & & & \multicolumn{4}{|c|}{ Field } & \multicolumn{4}{|c|}{ Greenhouse } \\
\hline & & & $\mathrm{p}>\mathrm{b}$ & $\mathrm{p}=\mathrm{b}$ & $\mathrm{p}<\mathrm{b}$ & $\chi^{2}$ & $\mathrm{p}>\mathrm{b}$ & $\mathrm{p}=\mathrm{b}$ & $\mathrm{p}<\mathrm{b}$ & $\chi^{2}$ \\
\hline Cucumis sativus & Cucumber & Vlaspik & 4 & 28 & 33 & $22.0 * * *$ & & & & \\
\hline Cucurbita pepo & Pumpkin & Baby Pam & 5 & 37 & 8 & $0.48^{\mathrm{NS}}$ & 8 & 120 & 10 & $0.13^{\mathrm{NS}}$ \\
\hline Cucurbita pepo & Acorn squash & $\begin{array}{l}\text { Royal Acorn } \\
\text { Squash }^{\mathrm{y}} \\
\text { Autumn Delight }^{\mathrm{y}}\end{array}$ & 2 & 81 & 4 & $0.38^{\mathrm{NS}}$ & 4 & 59 & 13 & $4.25^{*}$ \\
\hline Citrullus lanatus & Watermelon & Crimson Sweet & 2 & 43 & 10 & $4.68 *$ & & & & \\
\hline Cucumis melo & Melon & Odyssey & 22 & 36 & 12 & $2.65^{\mathrm{NS}}$ & & & & \\
\hline Cucurbita pepo & Zucchini & Black Beauty & 6 & 54 & 36 & $20.7 * * *$ & & & & \\
\hline Cucurbita pepo & Summer squash & $\begin{array}{l}\text { Horn of Plenty } \\
\text { Premium }\end{array}$ & 0 & 87 & 5 & $4.05 *$ & & & & \\
\hline
\end{tabular}

${ }_{\mathrm{z}} \mathrm{p}>\mathrm{b}, \mathrm{p}=\mathrm{b}, \mathrm{p}<\mathrm{b}$ : disease progression on peduncle end greater than, equal to, or less than blossom end, respectively.

y‘Royal Acorn Squash' (field), 'Autumn Delight' (greenhouse).

Ns, *, **, *** $\chi^{2}$ value nonsignificant, significant at $P \leq 0.05,0.01$, or 0.001 , respectively.

The transition from waxy green to green exocarp was accompanied by a marked reduction in susceptibility, suggesting that changes in exocarp properties with fruit development might influence susceptibility, although presumably many other changes are also occurring at this stage of development.

It was also observed that in Phytophthora-infested fields, the cucumber blossom end is more frequently infected than the peduncle end. While more frequent or earlier contact with the soil may be a contributing factor to this observation, we also observed a difference in susceptibility between the peduncle and blossom ends of fruit of several of the crops. The difference was most pronounced in three crops with the most elongated fruit: cucumber, butternut squash, and zucchini.

In conclusion, all the cucurbit crops tested exhibited an agerelated decrease in susceptibility to $P$. capsici, indicating that this is a general trait among diverse cucurbit crops and raises interesting questions about the possible underlying mechanisms. Information about age-related resistance can be helpful in developing better integrated pest management strategies (Develey-Rivière and Galiana, 2007; Ficke et al., 2002). Timing of chemical applications based when target tissue is most susceptible could allow for more effective disease control and minimize unnecessary chemical applications.

\section{Literature Cited}

Ando, K. and R. Grumet. 2006. Evaluation of altered cucumber plant architecture as a means to reduce Phytophthora capsici disease incidence on cucumber fruit. J. Amer. Soc. Hort. Sci. 131:491-498.

Babadoost, M. 2004. Phytophthora blight: A serious threat to cucurbit industries. 5 Mar. 2009. <http://www.apsnet.org/online/feature/ cucurbit/>.

Bird, G., B. Bishop, E. Grafius, M. Hausbeck, L. Jess, W. Kirk, and W. Pett. 2005. Insect, disease and nematode control for commercial vegetables. Michigan State Univ. Ext. Bul. E-312.

Century, K.S., R.A. Lagman, M. Adkisson, J. Morlan, R. Tobias, K. Schwartz, A. Smith, J. Love, P.C. Ronald, and M.C. Whalen. 1999. Developmental control of $\mathrm{Xa21}$-mediated disease resistance in rice. Plant J. 20:231-236.

Develey-Rivière, M.P. and E. Galiana. 2007. Resistance to pathogens and host developmental stage: A multifaceted relationship within the plant kingdom. New Phytol. 175:405-416.
Ficke, A., D.M. Gadoury, and R.C. Seem. 2002. Ontogenic resistance and plant disease management: A case study of grape powdery mildew. Phytophathology 92:671-675.

Gadoury, D.M., R.C. Seem, A. Ficke, and W.F. Wilcox. 2003. Ontogenic resistance to powdery mildew in grape berries. Phytopathology 93:547-555.

Gevens, A.J., K. Ando, K. Lamour, R. Grumet, and M.K. Hausbeck. 2006. Development of a detached cucumber fruit assay to screen for resistance and effect of fruit age on susceptibility to infection by Phytophthora capsici. Plant Dis. 90:1276-1282.

Hausbeck, M. and K. Lamour. 2004. Phytophthora capsici on vegetable crops: Research progress and management challenges. Plant Dis. 88:1292-1302.

Kennelly, M.M., D.M. Gadoury, W.F. Wilcox, P.A. Magarey, and R.C. Seem. 2005. Seasonal development of ontogenic resistance to downy mildew in grape berries and rachises. Phytopathology 95:14451452.

Kim, Y.J., B.K. Hwang, and K.W. Park. 1989. Expression of agerelated resistance in pepper plants infected with Phytophthora capsici. Plant Dis. 73:745-747.

Koch, M.F. and T.W. Mew. 1991. Effect of plant age and leaf maturity on the quantitative resistance of rice cultivars to Xanthomonas campestris pv. oryzae. Plant Dis. 75:901-904.

Kus, J.V., Z. Zaton, R. Sarkar, and R.K. Cameron. 2002. Age-related resistance in Arabidopsis is a developmentally regulated defense response to Pseudomonas syrinagae. Plant Cell 14:479-490.

Lamour, K.H. and M.K. Hausbeck. 2000. Mefenoxam insensitivity and the sexual stage of Phytophthora capsici in Michigan cucurbit fields. Phytopathology 90:396-400.

Mazzola, M., J.E. Leach, R. Nelson, and F.F. White. 1994. Analysis of the interaction between Xanthomonas oryzae pv. oryzae and the rice cultivars IR24 and IRBB21. Phytopathology 84:392-397.

McDowell, J.M., S.G. Williams, N.T. Funderburg, T. Eulgem, and J.L. Dangl. 2005. Genetic analysis of developmentally regulated resistance to downy mildew (Hyaloperonospora parasitica) in Arabidopsis thaliana. Mol. Plant Microbe Interact. 18:1226-1234.

Ngouajio, M., G. Wang, and M.K. Hausbeck. 2006. Changes in pickling cucumber yield and economic value in response to planting density. Crop Sci. 46:1570-1575.

Padley, L.D., Jr., E.A. Kabelka, and P.D. Roberts. 2009. Inheritance of resistance to crown rot caused by Phytophthora capsici in Cucurbita. HortScience 44:211-213.

Padley, L.D., Jr., E.A. Kabelka, P.D. Roberts, and R. French. 2008. Evaluation of Cucurbita pepo accessions for crown rot resistance 
to isolates of Phytophthora capsici. HortScience 43:19961999.

Panter, S.N. and D.A. Jones. 2002. Age-related resistance to plant pathogens. Adv. Bot. Res. 38:251-280.

Ristaino, J.B., G. Parra, and C.L. Campbell. 1997. Suppression of phytophthora blight in bell pepper by a no-till wheat cover crop. Phytopathology 87:242-249.

Steel, R.G.D. and J.H. Torrie. 1960. Principles and procedures of statistics. McGraw Hill, New York.

Ullah, Z. and R. Grumet. 2002. Localization of zucchini yellow mosaic virus to the veinal regions and role of viral coat protein in veinal chlorosis conditioned by the zym potyvirus resistance locus in cucumber. Physiol. Mol. Plant Pathol. 60:79-89.

Wai, T. and R. Grumet. 1995. Inheritance of watermelon mosaic virus resistance in the cucumber line TMG-1: Tissue-specific expression and relationship to zucchini yellow mosaic virus resistance. Theor. Appl. Genet. 91:699-706.

Wang, G. and M. Ngouajio. 2008. Integration of cover crop, conservation tillage, and low herbicide rate for machine-harvested pickling cucumbers. HortScience 43:1770-1774.

Whallen, M.C. 2005. Host defense in a developmental context. Mol. Plant Pathol. 6:347-360. 